UNIVERSIDADE DE SÃO PAULO

FACULDADE DE ECONOMIA, ADMINISTRAÇÃO E CONTABILIDADE DEPARTAMENTO DE CONTABILIDADE E ATUÁRIA PROGRAMA DE PÓS-GRADUAÇÃO EM CIÊNCIAS CONTÁBEIS

A INTERDISCIPLINARIDADE NO ENSINO E NA PESQUISA CONTÁBIL: UM ESTUDO DO MUNICÍPIO DE SÃO PAULO

Ivan Carlin Passos

Orientador: Prof. Dr. Edgard Bruno Cornachione Júnior

SÃO PAULO

2004 
Prof. Dr. Adolpho Jose Melfi

Reitor da Universidade de São Paulo

Profa. Dra. Maria Tereza Leme Fleury

Diretora da Faculdade de Economia, Administração e Contabilidade

Prof. Dr. Reinaldo Guerreiro

Chefe do Departamento de Contabilidade e Atuária

Prof. Dr. Fábio Frezatti

Coordenador do Programa de Pós-Graduação em Ciências Contábeis 
IVAN CARLIN PASSOS

\title{
A INTERDISCIPLINARIDADE NO ENSINO E NA PESQUISA CONTÁBIL: UM ESTUDO DO MUNICÍPIO DE SÃO PAULO
}

\author{
Dissertação apresentada ao Departamento de \\ Contabilidade e Atuária da Faculdade de \\ Economia, Administração e Contabilidade da \\ Universidade de São Paulo como requisito \\ para a obtenção do título de Mestre em \\ Ciências Contábeis.
}

Orientador: Prof. Dr. Edgard Bruno Cornachione Júnior 
Dissertação defendida e aprovada no Departamento de Contabilidade e Atuária da Faculdade de Economia, Administração e Contabilidade da Universidade de São Paulo - Programa de Pós-Graduação em Ciências Contábeis, pela seguinte banca examinadora:

Passos, Ivan Carlin

A interdisciplinaridade no ensino e na pesquisa contábil: um estudo do município de São Paulo / Ivan Carlin Passos. -- São Paulo, 2004.

$165 \mathrm{f}$.

Dissertação (Mestrado) - Universidade de São Paulo, 2004

Bibliografia.

1. Contabilidade - Estudo e ensino - São Paulo (SP) 2. Contabilidade Pesquisa - São Paulo (SP) 3. Interdisciplinaridade I. Faculdade de Economia, Administração e Contabilidade da USP II. Título.

CDD - 657 